\title{
O Odor Suspeito dos Mortos a a LiçÃo da Ciência Química: VICENTE Seabra e a Reforma dos Cemitérios
}

\author{
Ana Cristina Araújo \\ Faculdade de Letras da Universidade de Coimbra e Centro de História da Sociedade e da Cultura \\ uc4217@fl.uc.pt
}

\begin{abstract}
The suspicious odor of the dead and the lesson of Chemical Science: Vicente Seabra and the reform of cemeteries - This article focuses on the practical principles of the scientific debate on the breathable air and its impact on European public opinion, during the eighteenth century. It also aims to highlight the precursor nature of chemical theories about combustion, oxidation and respiration of living organisms supported by Vicente Seabra in his works. This remarkable professor of Chemistry at the University of Coimbra wrote the Memoria sobre os prejuisos causados pelas sepulturas dos cadaveres nos templos, e methodo de os prevenir (1800). In this book, he discussed the scientific reasons for the reform of cemeteries and he joined the enlightenment ideas of the modern European movement that advocated cremation. In fact, Vicente Seabra is the precursor of the idea of creating crematoriums in cemeteries in Portugal. This idea would be adopted by the government and implemented in the Portuguese capital only in the twentieth century.
\end{abstract}

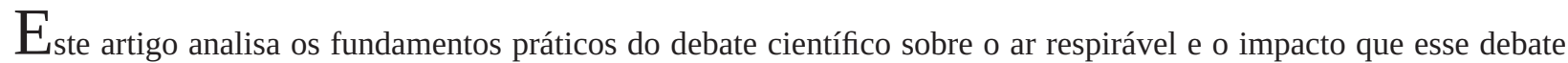
teve na opinião pública europeia, no século XVIII. Pretende salientar também o carácter percursor das teorias químicas sobre a combustão, oxidação e respiração dos organismos vivos sustentadas por Vicente de Seabra nas suas obras. Em defesa da reforma dos cemitérios em Portugal, este notável professor de Química da Universidade de Coimbra escreveu a Memoria sobre os prejuisos causados pelas sepulturas dos cadaveres nos templos, e methodo de os prevenir (1800). Neste livro, retoma as esclarecidas propostas do moderno movimento cremacionista europeu. Para todos os efeitos, Vicente de Seabra é o percursor, em Portugal, da ideia de criação de fornos crematórios nos cemitérios, ideia que viria a ser adoptada pelo governo e posta em prática na capital portuguesa apenas no século XX.

\section{Ar Respirável e Intolerância Olfactiva: Sensibilidades E IDEIAS DO SÉCULO XVIII}

O triunfo generalizado das ideias de tolerância religiosa e civil ocorre, no século XVIII, ao mesmo tempo que despontam, no seio das sociedades europeias, complexas manifestações de intolerância, ligadas ao corpo, mais concretamente à linguagem dos sentidos e à percepção física de estados de salubridade e de insalubridade. A história vivida da repulsa olfactiva, particularmente evidente em meio urbano, radica num conjunto diverso de motivações de índole "científica", supostamente fundadas em múltiplas observações e escassas evidências empíricas. À medida que foram crescendo as preocupações com o corpo saudável, os maus odores, tolerados durante séculos a fio, tornaram-se insuportáveis para a burguesia urbana setecentista, passando a ser tomados como factor de perigo público, motivo de repulsa para narizes mais educados e objecto de estranhas suposições e teorias.

Alain Corbin, que explorou de forma sistemática a lógica dos odores na sociedade Europeia, nos séculos XVIII e XIX, reuniu abundantes testemunhos dessa semiologia olfactiva e, à luz do quadro normativo e científico dessas épocas,

Este artigo retoma e aprofunda o texto que apresentamos ao Colóquio sobre História da Química em torno de Vicente Seabra, realizado no Museu da Ciência da Universidade de Coimbra, a 1 de Abril de 2016. Agradeço ao Doutor Sérgio Paulo Jorge Rodrigues a cuidada leitura crítica do texto. estudou as consequências práticas das trocas de odores nos espaços habitados, privados e públicos [1]. No campo específico da higiene e da medicina, outros estudos revelam que a História desta ciência não ficou imune a inúmeras fantasias que povoaram o imaginário social e que há relatos surpreendentes tanto por detrás de falsas teorias como na génese de assinaláveis descobertas científicas [2].

Como é sabido, antes das demonstrações científicas de Lavoisier, médicos, físicos e demais cultores do conhecimento experimental procuravam compreender a composição e o comportamento do ar. Partilhavam a ideia de que o ar era uma substância fluida elementar, pesada e elástica e que "la fluidité de l'air fait que ses parties cédent au moindre effort; ainsi les corps s'y meuvent-ils aisément, les sons s’y propagent et les odeurs s'y diffusent” [3].

Uma vez reconhecidas as virtudes elásticas do ar, admitia-se que existiam na atmosfera, em suspensão, emanações, eflúvios e substâncias diversas. A par desta composição essencial, generalizara-se também a convicção de que o ar era, por excelência, o lugar de expansão do flogístico, invisível e inflamável, sendo por esta razão indispensável à vida. A noção de flogístico, elaborada por Georg-Ernest Sthal, nos inícios do século XVIII, alicerçava-se no princípio do fogo, possibilitando a organização de um sistema coerente de reações de natureza química [4]. Neste sistema, o ar, esse fluido insondável a que Boyle dedicou, sem êxito, muitas horas de observação, continuava a ser, ainda assim, 
um enorme enigma para “aeristas”, higienistas e químicos. Segundo Boyle, o ar continha uma "substance vitale et singulière, que nous ne connaissons pas" e que "lorsqu'on renferme l'air dans quelque vaisseau de métal ou dans un verre, il y reste sans qu'il lui arrive aucun changement, \& toûjours sous la forme d'air: mais il n'en est pas de même des vapeurs; car dès qu'elles deviennent froides, elles perdent toute leur élasticité, \& vont s'attacher tout autour des parois internes du verre, d'où elles dégoûtent \& tombent ensuite en bas; de sorte que les verres \& les vaisseaux, qui auparavant étoient remplis de vapeurs élastiques, se trouvent ensuite comme vuides. Il en est à peu-près de même des exhalaisons des autres corps, qui se dissipent avec le tems \& se perdent en quelque maniere, lorsque leurs parties, après avoir perdu l'élasticité qu'elles avoient, viennent à se réunir \& à ne faire qu'un corps” [5].

Mas, a partir dos anos sessenta do século XVIII, pouco antes de Lavoisier analisar os fenómenos orgânicos da combustão, algumas observações centradas em reações fisiológicas e na ideia de saneamento do ar respirável, tendem a modificar o horizonte de reflexão da química. Priestley, um dos grandes mentores da nova química, dita pneumática, tenta medir a degradação do 'ar comum' utilizado pela respiração e a produção do 'ar flogístico’ (nitrogénio) e do 'ar fixado' (dióxido de carbono) à custa do 'ar vital', desflogístico (oxigénio) [6]. Apesar da sua ligação à teoria do flogístico, Pristley alimenta a pré-compreensão científica do ar como combinação de gases de diferentes composições químicas. A sua concepção não anulava, todavia, a ideia tradicionalmente aceite do ar como mistura imprecisa de fumaças, enxofres, vapores aquosos, voláteis e salinos que exalavam da terra e dos corpos. Porém, as múltiplas observações levadas a cabo por ele e por outros seguidores da química pneumática permitiram não só recolher, isolar e identificar uma série de gases como detectar reações vitais de organismos animais expostos à acção dos mesmos gases. Em resultado das “descobertas” que se foram fazendo em torno do "ar fixado” (dióxido de carbono), do "ar inflamável” (hidrogénio), do “alcalino volátil” (amoníaco) e do “ar ácido vitríolo”, (ácido sulfuroso, ou dióxido de enxofre na nomenclatura de Vicente Seabra), generalizou-se a ideia de senso comum de que existiam duas grandes categorias de ares: os respiráveis e os corrompidos [7]. Para a aferição de uns e outros, o odor tinha uma importância primacial, sendo certo que para o vulgo e para os sábios, sem distinção, a vigilância olfactiva derivava da percepção imprecisa de processos mal identificados de putrefacção e fermentação que afectavam a atmosfera e eram nocivos para a saúde das populações.

\section{Exalações Mefíticas, Miasmas e Cemitérios: Inícios da Campanha Higienista em Portugal}

O temor de exalações mefíticas e a associação de miasmas e odores pútridos a febres, epidemias e acidentes mortais reforçava assim a necessidade de se encontrarem antídotos eficazes para combater a chamada corrupção do ar. Por isso, os químicos procuravam febrilmente o antimefítico que fosse capaz de debelar, ao mesmo tempo, o mau chei- ro, o fedor asfixiante e o risco mórbido. A promoção de desinfectantes e/ou desodorizantes químicos acarretou a vulgarização do vinagre e o recurso a fumigações diversas - note-se que as fumigações combinam os efeitos benéficos do fogo a substâncias específicas - em espaços públicos saturados e expostos a fenómenos de contágio de difícil controlo. É também sabido que o essencial dos textos e dos debates suscitados por estas situações extremas apontava para a ameaça que representavam as concentrações de excrementos e cadáveres nas cidades. Compreende-se, portanto, que a vigilância olfactiva de governantes e de conselheiros políticos se exerça, de meados do século XVIII em diante, sobre os locais simultaneamente infectos e sagrados, como eram as igrejas, onde coabitavam os vivos e os mortos nelas enterrados, e os cemitérios, ou melhor, os carneiros em que se sepultavam, em diferentes estratificações, vários cadáveres e as valas comuns em redor dos templos.

Neste quadro importa referir os primeiros ecos da campanha higienista em Portugal, campanha que tendo como fulcro a questão dos cemitérios se inicia, em França, com a publicação, em 1743, das famosas Lettres sur les sépultures dans les églises (1743) do abade Porée [8]. Este texto, pioneiro para o repensamento da geografia cemiterial, é conhecido e discutido em Portugal, poucos anos depois, como revelam as primeiras obras publicadas em defesa do saneamento das sepulturas nas igrejas [9].

O médico José Alvarez da Silva no opúsculo intitulado: Precauções Medicas contra algumas remotas consequências que se podem excitar do Terremoto de 1755 (1756), denuncia, abertamente, "o grande dano a que se expõem os homens enterrando nos templos os cadáveres" [10]. Sensível aos conselhos do abade Porée e leitor atento da Encyclopédie, Alvarez revela estar também a par dos estudos médicos produzidos nas escolas de Gottïngen e de Edimburgo. Em defesa do saneamento urbano e da saúde das populações defende assim a criação de cemitérios públicos.

Ainda no rescaldo do terramoto, outro médico, António Nunes Ribeiro Sanches, dedica um capítulo do seu Tratado da Conservação da Saúde dos Povos (1756) à questão dos cemitérios, citando avulsamente as observações e advertências do abade Porée. Com base na literatura médica e química mais avançada, Sanches advoga a separação dos mortos da cidade dos vivos e a construção de cemitérios públicos em lugares ermos e ventilados, situados na periferia de grandes ou pequenos aglomerados populacionais [11]. O sistema tradicional de inumação, indecoroso para a própria dignidade do culto - na perspectiva de Ribeiro Sanches - é pouco depois objeto de pública contestação por parte do Provedor-Mor da saúde de Lisboa, Luís de Vasconcelos e Sousa que avança, em 1771, sem êxito, com uma proposta de criação de um cemitério público em Lisboa [12], sem mencionar todavia o projeto do primeiro espaço do género instituído em Vila Real de Santo António, após o terramoto de 1755. 
Os primeiros passos para a alteração da geografia cemiterial estavam dados, mas continuá-los revelar-se-ia mais difícil. Na década de oitenta, por intervenção de Pina Manique, iniciam-se os trabalhos preparatórios para a criação de dois cemitérios modernos em Lisboa. Aconselhado pelo famoso naturalista e médico Manuel Henriques de Paiva que havia sido aluno e mestre de oficina do laboratório químico da Universidade de Coimbra - o Intendente Geral da Polícia reúne os primeiros dados estatísticos para a elaboração de um mapa necrológico da capital portuguesa. Esse levantamento inicia-se em 1789 e é com base nos resultados apurados que Pina Manique encomenda aos higienistas Inácio Tamagnini e Manuel Luís Alvares de Carvalho a escolha dos terrenos apropriados para as novas construções. Em resultado dessa consulta, o decreto de 5 de Abril de 1796 prevê, para o efeito, a aquisição de dois espaços, um em Campo de Ourique (Prazeres) e outro na Penha de França (Alto de S. João). Entretanto, há notícia de encerramentos temporários e de inspeções a alguns cemitérios conventuais e paroquiais urbanos, medidas que virão a ser retomadas décadas mais tarde e que, em regra, foram motivadas por mortes por inalação de gases saídos das sepulturas [13]. Enfim, as medidas pontuais, os projetos e os planos gizados no último quartel do século revelar-se-iam, com passar dos anos, indispensáveis, embora persistissem, quase sempre agravados por preconceitos de natureza mágico-religiosa, sérios bloqueios à reforma dos cemitérios.

Vicente Seabra e a sua Memoria sobre os Prejuisos Causados pelas Sepulturas dos Cadaveres nos Templos

Neste contexto, e antecedendo o ressurgimento, em vésperas das Invasões Francesas, de novas propostas de edificação de cemitérios, seculares e públicos, por alvará de 17 de Março de 1805 e por decreto de 21 de Setembro de 1806, Vicente Coelho de Seabra da Silva Teles publica, no ano de 1800, na Tipografia Calcográfica do Arco do Cego, portanto com a proteção do ministro D. Rodrigo de Sousa Coutinho, a Memoria sobre os prejuisos causados pelas sepulturas dos cadaveres nos templos, e methodo de os prevenir (Figura 1). Trata-se de um texto singular, concebido com base nos mais modernos ensinamentos da Química, e que participa, com fundadas razões, no debate europeu sobre a nocividade das necrópoles tradicionais [14].

O seu autor, Vicente Coelho de Seabra fez parte da brilhante geração universitária que ideou formar, em Coimbra, uma Sociedade Patriótica destinada a promover o bem público e a difundir os progressos das ciências, a que pertenceu também Manuel Henriques de Paiva [15]. Ambos se formaram em Filosofia Natural e Medicina, tendo Vicente de Seabra depois de publicar o primeiro volume de Os Elementos de Chimica, em 1788, obtido o doutoramento na primeira daquelas Faculdades [16]. Ao longo do seu cursus honorum académico opôs-se "aos que querem saber tudo, e tudo querem julgar, sem nada se atreverem a escrever" - conforme esclarece no preâmbulo aos Elementos de Chimica - vindo a ocupar, por mérito próprio, o lugar de lente substituto de Química e Metalurgia, em 1793, depois de ter passado pelo laboratório chimico como demonstra-

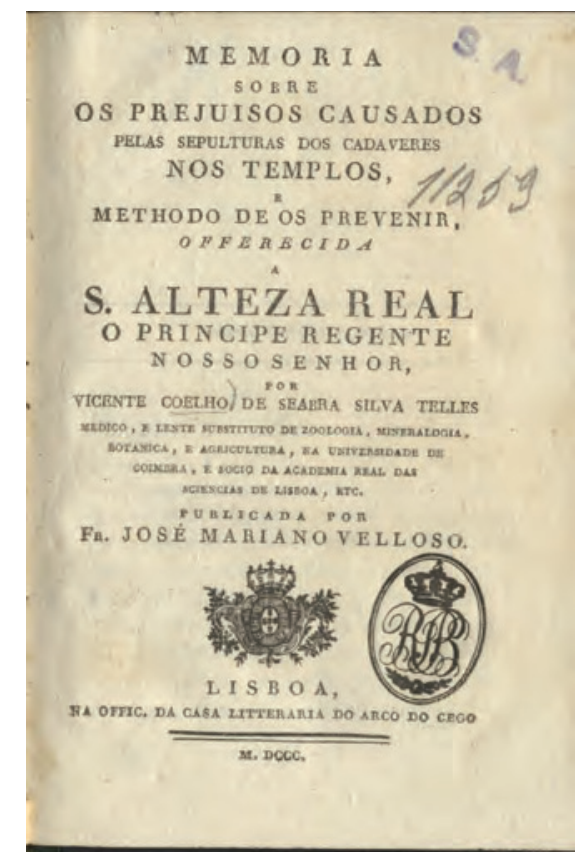

Figura 1 - Memoria sobre os prejuisos causados pelas sepulturas dos cadaveres nos templos, e methodo de os prevenir (1800), de Vicente de Seabra

dor [17]. Conhecedor das experiências e descobertas mais avançadas realizadas por Lavoisier, Berthollet e Fourcroy, Vicente de Seabra tornou-se um adepto confesso das teses daqueles autores. Partilhando com Henriques de Paiva, com quem teve alguns desaguisados científicos, o desejo de comunicar e tornar útil o conhecimento científico, mormente em matérias tão sensíveis como a higiene e a saúde pública, reconhece que "seria desnecessário" escrever a Memoria sobre os prejuisos causados pelas sepulturas dos cadaveres nos templos... se as luzes das Sciencias Naturaes estivessem assas espalhadas” em Portugal [18]. A esta razão junta aquilo a que chama "piedade mal entendida”, que fazia dos "lugares santos", espaços "pavorosos e impuros" e focos visíveis de "inumeráveis doenças” [19].

Neste ponto, a memória do homem de ciência era preenchida pela evocação das reflexões higienistas de Ribeiro Sanches e de Vicq d'Azir e pela recordação próxima de ocorrências de contágios e acidentes mortais em cemitérios localizados no Porto e nas imediações da cidade de Coimbra. Deles dá testemunho na primeira pessoa: "referirei somente - diz Vicente de Seabra -, a grande epidemia acontecida na cidade do Porto, não ha muitos annos, e causada pela emanação podre da Igreja de Santo Ildefonso, em que, para ser destruída a dita emanação foi preciso ter muito tempo as portas abertas de noute, e de dia com sentinelas ao pé, queimar vinagres, lava-la etc. etc.” [20]. Regista também uma outra epidemia no Porto, em 1779, causada pela libertação de gases mefíticos da igreja dos Orfãos e menciona que, por volta de 1795, todas as povoações da margem esquerda do Mondego, do Amial até Verride, haviam sido atingidas por "uma febre podre". Nessa ocasião, diz, "eu estive quase sendo vítima, e serião povoações inteiras, se não fosse a suma caridade e sabias Providencias do Excelentissimo Bispo Conde; da qual não pude descobrir outra origem senão a igreja de Alfarelos, 
assás immunda, e indecente; em cujo lugar apparecêrão os primeiros inficcionados " [21].

Não sabemos, em concreto, a cronologia e a natureza das medidas de saúde pública - a expressão é sua - adoptadas nas localidades mencionadas, por iniciativa do reitor da Universidade e bispo conde de Arganil, embora admitamos que a par do arejamento e do recurso a fumigações nos sítios afectados se tenha ainda procedido à renovação de terras nos locais de inumação [22]. Esta era, de resto, uma das práticas mais correntes nos países em que se iniciara a "revolução dos cemitérios”, França e Áustria, e que Vicente de Seabra recomenda na Memoria sobre os prejuisos causados pelas sepulturas dos cadaveres nos templos... para obviar ao tradicional costume de se empilharem cadáveres em fossas a pouca profundidade e em grande quantidade, com evidentes danos para a sanidade dos espaços sagrados e para a qualidade do ar respirável nos templos.

Conhecedor, conforme explicita, dos "progressos espantosos” da "Chimica moderna”, Vicente de Seabra propõe-se examinar, na referida Memória, os seguintes aspectos: “os elementos dos corpos organizados; as substâncias em que se resolvem depois de mortos; o efeito dellas sobre a economia animal; o seu estado dentro dos templos; e o meio para evitar os seus efeitos” [23].

Na esteira das concepções de Lavoisier sobre a combustão, oxidação e respiração e tirando especialmente partido da análise de Berthollet sobre os gases libertados em processos de putrefacção, Vicente de Seabra começa por afirmar que “ o carbonico, oxygenio, azoto e hydrogenio, combinados em diversas porções, dão origem a todas as partes dos entes organisados e que os animaes differencião-se dos vegetaes pela maior copia de azoto, acido phosporico e cal nelles sempre existentes” [24]. Mais adiante, insistindo na composição química de base de todos os corpos naturais e no efeito de degradação, morte e nascimento dos seres vivos e matéria inanimada deixa subentendido a sua adesão ao princípio de Lavoisier, preferindo, em todo o caso, citar Beccher que tivera a intuição desse movimento ininterrupto e cíclico e que o plasmara na expressão "circulus aeterni motus”, lema igualmente retomado por Fourcroy no Système des Coinnaissances Chimiques et de leurs applications aux phénomènes de la nature et de l'art (1801).

Admite assim que "os animaes pela podridão se resolvem nos seus elementos, cuja maior parte entra em novas combinações, de que resultão o amoníaco, a emanação putrida, o gaz acido carbónico [dióxido de carbono], gaz hydrogenio, gaz azótico, acido nítrico, phosphato de cal [fosfato de cálcio], e de soda [sódio], carbonico e materias oleosas" [25]. Destes produtos uns são fixos e outros voláteis, sendo manifesta, conforme demonstra, a perigosidade do gaz acido carbónico, “invisível” e “duas vezes mais pesado que o ar puro, [oxigénio]” [26]. Acrescenta ainda que este gás não inflamável misturado com oxigénio produzia efeitos mortíferos, efeitos comprovados por inúmeras experiências e ocorrências descritas na literatura científica da época [27]. Quando ao gás acido carbónico se associava outro principio assaz nocivo, isto é, a "emanação pútrida”, formando mortíferas concentrações de gases e odores para a saúde pública, os cientistas estavam eticamente obrigados a denunciar essas situações [28].

Vicente de Seabra fê-lo, mesmo sabendo que a "sensação do olfato" não podia medir-se nem padronizar-se. Dito de outro modo, sabia que os odores escapavam às malhas da linguagem científica, embora Fourcroy tivesse afirmado, em 1798, que o odor derivava da dissolução do corpo odorante no ar ou num líquido [29], ou seja, dependia da particular volatilidade e solubilidade de cada substância. Nesta óptica desvaloriza-se o olfacto como factor isolado de avaliação do pútrido, ou melhor, o olfacto é reduzido à categoria de indicador, nem sempre único ou determinante da qualidade respirável do ar, ao contrário do que acontecera décadas antes.

Apesar de estar em perfeita sintonia com tantas e tão espantosas descobertas, Vicente de Seabra não deixava de avaliar, com enorme realismo, as condições de receptividade às suas ideias em matéria de reforma dos cemitérios. A este propósito escrevia: "Não nos resta pois outro partido senão sujeitar-nos á opinião publica que somente o tempo e as circunstancias podem mudar” [30].

O que propõe então Vicente de Seabra para contrariar os danos causados pelos cemitérios tradicionais? As suas propostas delineiam quatro caminhos historicamente possíveis, mas em tempos históricos diferentes. As suas preferências identificam-se com as que atualmente vigoram na sociedade portuguesa, incluindo a cremação - conquista bem tardia [31]. Em síntese, advoga como melhor solução para a saúde pública a destruição pelo fogo “dos cadáveres imediatamente antes que apodreçam” [32]. Integra-se assim, de forma esclarecida e prática, no moderno movimento cremacionista europeu que teve o seu momento inaugural com Scipione Patiolli, autor de Il Saggio Intorno al Luogo del Seppellire (1774), obra que Vicente Seabra conhecia. Preferindo a incineração à inumação dos cadáveres, o químico português combina, todavia, esse meio eficaz de aniquilamento dos despojos físicos com a construção de grandes cemitérios, concebidos segundo as melhores normas de higiene, onde pudessem existir sepulcros de família, espaços de conservação das cinzas dos mortos e até, em casos especiais, locais de deposição de corpos embalsamados. Por último, e como recurso para evitar "ao menos os terríveis damnos de huma tão mal entendida piedade" [33], sustenta o saneamento dos templos que serviam de necrópoles, com remoção de terras, renovação de campas, restrições ao sepultamento de um número avultado de cadáveres na mesma fossa, regulação de profundidade dos enterramentos e utilização de cal viva sobre os mesmos.

Esta última alternativa, nem sempre observada, terá permito arrastar, com naturais resistências, a questão da reforma dos cemitérios até 1835, ano em que Rodrigo da Fonseca Magalhães assina os decretos de 21 de Setembro e de 8 de Outubro que estão na origem da criação dos primeiros cemitérios públicos em Portugal. 


\section{REFERÊNCIAS}

[1] A. Corbin, "Le miasme et la jounquille. L'odorat et l'imaginaire social XVIIIe-XIXe siècles”, Flammarion, Paris, 1982

[2] G. Vigarello, "História das práticas de saúde. A saúde e a doença desde a Idade Média”, Editorial Notícias, 2001 (1. ${ }^{\text {a }}$ ed. francesa 1993) e M.G. Grmek (dir.), "Histoire de la pensée médicale en Occident. De la Renaissance aux Lumières”, Éditions du Seuil, 1996

[3] R. Locqueneux, Gaz, "Dictionnaire Européen des Lumières”, PUF, Paris, 1997, 567

[4] F. Hoefer, "Histoire de la chimie", Firmin-Didot, Paris 1869 e B. Bensaude-Vincent \& I. Stengers, "Histoire de la chimie”, La Découverte, Paris, 1992

[5] D’Alembert e Formey, no artigo “Air” da Encyclopédie (I. 225), concluíam que "cela paroît par plusieurs expériences qui ont été faites par M. Boyle avec l'air que l'on tire des raisins, de la pâte de farine, de la chair, \& de plusieurs autres corps: cela se confirme aussi par les expériences dont M. Hales a donné la description dans son ouvrage intitulé la Statique des végétaux \& l'analyse de l'air ", http://artflsrv02.uchicago.edu/cgi-bin/philologic/getobject. pl?c.0:1000.encyclopedie0416 (Diderot and d'Alembert, Encyclopédie, ou dictionnaire raisonné des sciences, des arts et des métiers (1751-72); acedido a 13-03-2016)

[6] A. Corbin, op. cit.,16

[7] B. Bensaude-Vincent, Chimie, "Dictionnaire Européen des Lumières”, PUF, Paris, 1997, 241

[8] M. Vovelle, "La mort t l'Occident de 1300 à nos jours", Gallimard, Paris, 1983, 463

[9] A.C. Araújo, "A Morte em Lisboa. Atitudes e representações (1700-1830)”, Editorial Notícias, Lisboa, 1997, 372

[10] J.A. da Silva, "Precauções medicas contra algumas remotas consequencias, que se podem excitar do terremoto de 1755”, Offic. de Joseph da Costa Coimbra, Lisboa, 1756, 10

[11] A.N.R. Sanches, "Tratado da Conservação da Saúde dos Povos: obra util, e igualmente necessária a os magistrados, capitaens generais, capitaens de mar, e guerra, prelados, abadesssas, medicos, e pays de familia. Com hum appendix sobre os Terremotos", in “Obras”, vol 2, Acta Universitatis Conimbrigensis, 1966, 231-232

[12] A.C. Araújo, op. cit., 373

[13] A.C. Araújo, op. cit., 372-381; F. Catroga, "O Céu da Memória. Cemitério Romântico e Culto Cívico dos Mortos”, Livraria Minerva Editora, Coimbra, 1999, 42-48 e V. M. L. Dias, "Cemitérios, Jazigos e Sepulturas. Estudo Histórico, Artístico, Sanitário e Jurídico”, edição do autor, Coimbra, 1963, 80-83

[14] Vicente Coelho de Seabra da Silva Telles, "Memoria sobre os prejuisos causados pelas sepulturas dos cadaveres nos templos, e methodo de os prevenir”, Offic. Litteraria do Arco do Cego, Lisboa, 1800

[15] A.C. Araújo, Cosmopolitismo e Patriotismo. A propósito dos Estatutos Literários e Económicos da Sociedade dos mancebos Patriotas de Coimbra, in R. L. Garnel e A. L. Oliva (org.), Tempo e História, ideias e políticas: estudos para Fernando Catroga, Almedina, Coimbra, 2015, 325-350

[16] A.J. Andrade Gouveia, Químico Escarecido Luso-brasileiro. Vicente de Seabra (1764-1804), Memorias da Academia das Ciências de Lisba, Tom. XXI, Lisboa, 1976/77, 22-26 e A. M. Amorim da Costa, Vicente de Seabra. Filósofo Agricultor e Patriota, Química - Boletim da SPQ 136 (2015) 41-50

[17] A.M. Amorim da Costa, Da natureza do fogo e do calor na obra de Vicente Seabra (1764-1804), "Universidade(s). História, Memória, Prespectivas. Actas do Congresso História da Universidade. $7^{\circ}$ Centenário”, Coimbra, 1991, vol. 3,137-151

[18] Vicente Coelho de Seabra da Silva Telles, op. cit., 3

[19] Vicente Coelho de Seabra da Silva Telles, op. cit., 2

[20] Vicente Coelho de Seabra da Silva Telles, op. cit., 12

[21] Vicente Coelho de Seabra da Silva Telles, op. cit., 13

[22] Em abono desta hipótese regista este precedente: "entre nós se fez a renovação das terras das sepulturas da Igreja da Ordem III de S. Francisco do Convento de Jesus da cidade de Lisboa, Vicente Coelho de Seabra da Silva Telles, op. cit., 30

[23] Vicente Coelho de Seabra da Silva Telles, op. cit., 3

[24] Vicente Coelho de Seabra da Silva Telles, op. cit., 3-4

[25] Vicente Coelho de Seabra da Silva Telles, op. cit., 11

[26] Vicente Coelho de Seabra da Silva Telles, op. cit., 14. Actualmente sabemos que que o dióxido de carbono é cerca de 7/5 mais pesado que o oxigénio.

[27] Sabe-se hoje que numa mistura de dióxido de carbono com oxigénio forma-se monóxido de carbono, venenoso em pequenas quantidades.

[28] Identificando o luxo e a pompa fúnebre com um modelo, ainda em vigor, de anquilosada piedade católica, Vicente Coelho de Seabra sustenta que os efeitos devastadores dos cemitérios "serião irremediáveis se a Philosophia Natural, a quem a humanidade deve tantos auxilios, não nos sugerisse os meios de evitallos, ou ao menos de diminuillos”, Vicente Coelho de Seabra da Silva Telles, op. cit., 22

[29] A. Corbin, op. cit., 147

[30] Vicente Coelho de Seabra da Silva Telles, op. cit., 25

[31] A indicação encontrada na obra de Vicente de Seabra (1800) atesta a precocidade do movimento precursor a favor da cremação em Portugal, - note-se que, na mesma altura, decorria em França o debate público sobre a cremação. A apologia da cremação ressurge na opinião pública portuguesa em 1856, data em que se publica um artigo sobre o tema na revista o Instituto, o qual esteve na origem da campanha que teve o seu tempo forte na República. Admite-se que o primeiro forno crematório tenha sido instalado em Lisboa no final da segunda década do século vinte. Sobre o assunto veja-se, F. Catroga, op. cit., 279-291.

[32] Vicente Coelho de Seabra da Silva Telles, op. cit., 23

[33 ] Vicente Coelho de Seabra da Silva Telles, op. cit., 2

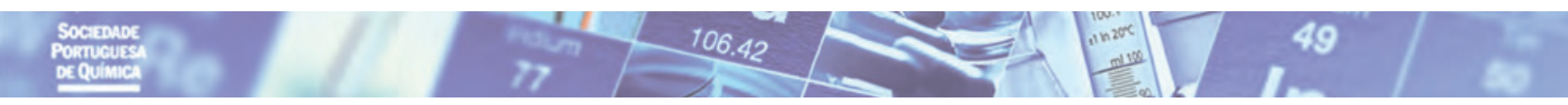




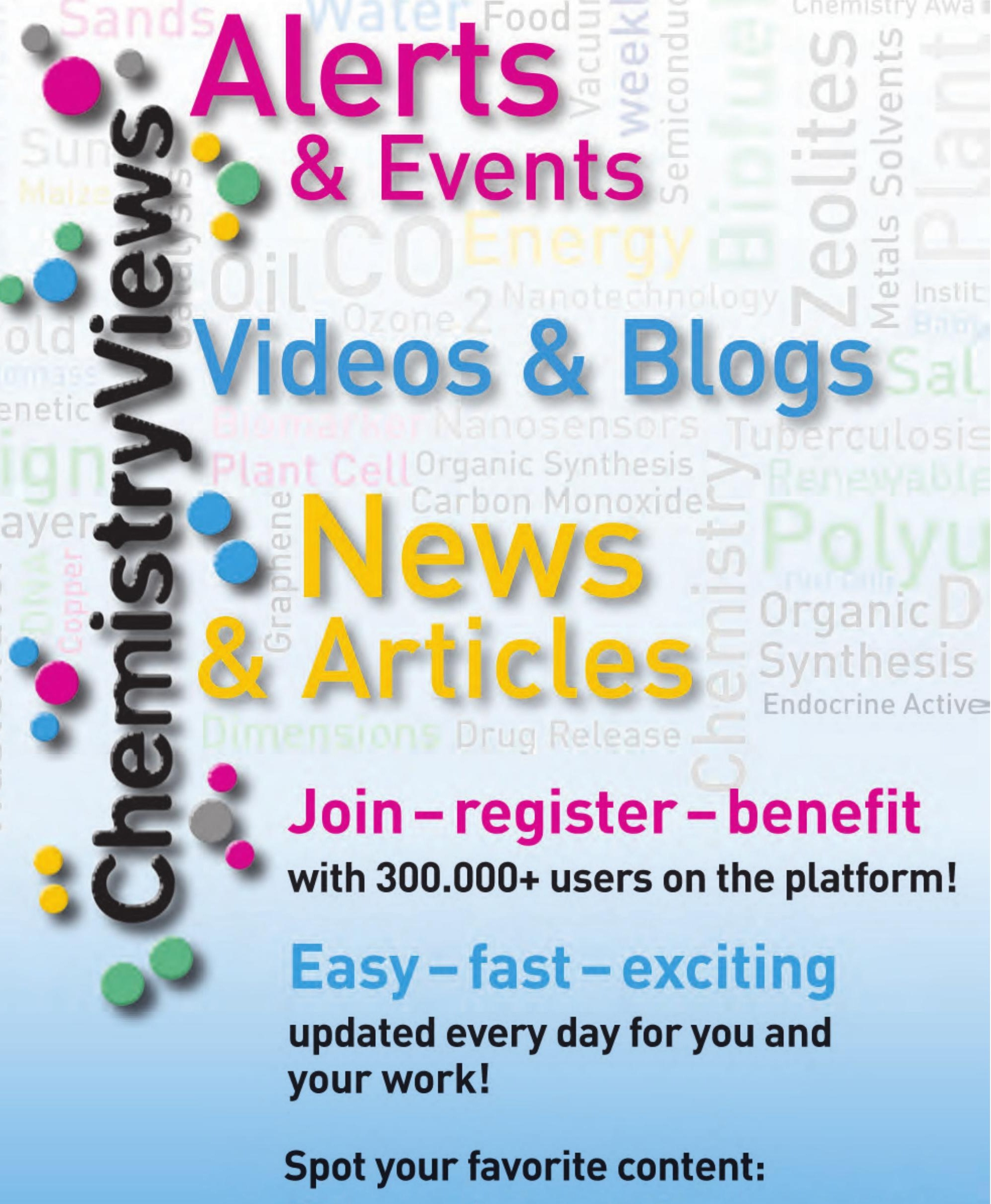

$\frac{5}{5}$ 